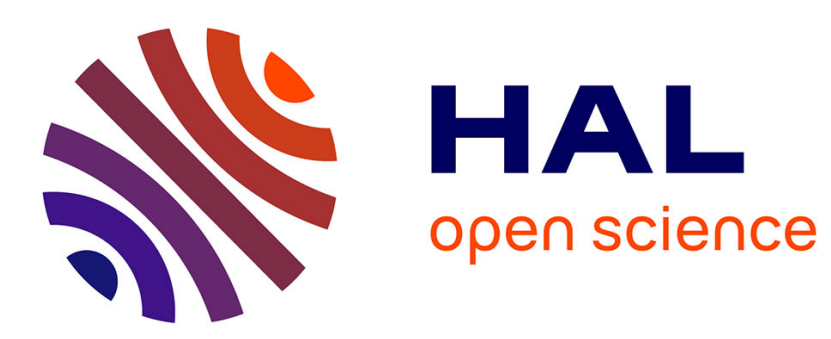

\title{
An update about artificial mastication
}

\author{
Marie-Agnès Peyron, Alain Woda
}

\section{To cite this version:}

Marie-Agnès Peyron, Alain Woda. An update about artificial mastication. Current Opinion in Food Science, 2016, 9, pp.21-28. 10.1016/j.cofs.2016.03.006 . hal-01594489

\section{HAL Id: hal-01594489 \\ https://hal.science/hal-01594489}

Submitted on 26 Sep 2017

HAL is a multi-disciplinary open access archive for the deposit and dissemination of scientific research documents, whether they are published or not. The documents may come from teaching and research institutions in France or abroad, or from public or private research centers.
L'archive ouverte pluridisciplinaire HAL, est destinée au dépôt et à la diffusion de documents scientifiques de niveau recherche, publiés ou non, émanant des établissements d'enseignement et de recherche français ou étrangers, des laboratoires publics ou privés.

\section{(a)(1) $\$$}

Distributed under a Creative Commons Attribution - NonCommercial - NoDerivatives| 4.0 


\section{An update about artificial mastication Marie-Agnès Peyron ${ }^{1,2}$ and Alain Woda ${ }^{3,4}$}

Developing masticatory apparatus, chewing robots or an artificial mouth is an old but ever more important goal in food science, nutrition or dental research fields, as reflected by the number of existing digital or biomechanical systems. Whatever the objective of the approach, basic knowledge of the physiology of mastication, adaptation and neurophysiological control is absolutely needed before conceiving an apparatus. Obviously, the final step in the development of a mastication simulator is its validation before performing food or food bolus characterization. This validation step is imperative to avoid biased interpretation and can be performed through in vivo-in vitro comparison of particle size distributions in food boluses obtained after normal mastication. This kind of validated machine offers the chance to produce boluses for other related uses such as nutrient bioaccessibility or digestion studies, for example. Such an apparatus can also be employed to simulate different dental states or ageing conditions.

\footnotetext{
Addresses

${ }^{1}$ National Institute of Agronomic Research, Joint Research Unit 1019 for Human Nutrition, Saint Genès Champanelle, France

${ }^{2}$ Clermont University, University of Auvergne, Joint Research Unit

1019 for Human Nutrition, Clermont-Ferrand, France

${ }^{3}$ Clermont University, University of Auvergne, CROC EA 4847, Clermont-Ferrand, France

${ }^{4} \mathrm{CHU}$ Clermont-Ferrand, Odontology Service, Clermont-Ferrand, France
}

Corresponding author: Peyron, Marie-Agnès

(marie-agnes.peyron@clermont.inra.fr)

Current Opinion in Food Science 2016, 9:21-28

This review comes from a themed issue on Sensory science and consumer perception

Edited by Susana Fiszman

http://dx.doi.org/10.1016/j.cofs.2016.03.006

2214-7993/C 2016 Elsevier Ltd. All rights reserved.

\section{Introduction}

Two main driving-objectives can be identified while simulating mastication: firstly, when the goal is to improve knowledge, to reproduce the biomechanical aspects of the masticatory system or to analyze the effect of forces, movements or constraints, for example. It generally results in the development and the use of mathematical models alone in an in silico approach or associated with mechatronic techniques to develop robots for biomechanical studies. Secondly, in very different approaches, simulators can be used to study either food bolus characteristics or to produce boluses for subsequent analyses (Figure 1).

Despite the important understanding gathered in several aspects of the masticatory process, simulation of mastication in the area of food science has, too often, been over-simplified and reduced to grinding, probably due to the lack of knowledge of physiology. This review resumes the main physiological key points of masticatory process, and describes the different existing simulations with biomechanical and modalities of functioning.

\section{Mastication must be understood before being simulated}

Through a complex and well-coordinated sensory-motor and visceral activities, mastication of a solid mouthful results in a bolus made of particles reduced in size, moistened enough to be cohesive, plastic to avoid particle aspiration, and to permit passage through the throat without discomfort or pain. The sensory-motor and visceral program is continually commanded by the central nervous system. The food properties are sensed as early as the first bite and, through sensory-motor feedback, the masticatory program is adjusted to the changes in bolus features occurring along the masticatory process. This highly complex and feedback-dependent dynamic complicates any attempt to reproduce instrumentally mastication. Therefore, advanced knowledge about how food structure influences the pattern of oral processing is required. Food is a complex stimulus, but the physical dimensions modulating the oral processing are limited to its hardness, its rough rheological dimensions (plasticity, elasticity or brittle nature for example), and size of the mouthful. Briefly, an increase in food hardness as well as in mouthful size leads to an increase in the number of masticatory cycles (tooth strokes) and applied muscle forces, whatever the rheological nature of the food. On the other hand, the rheological properties of food seem mostly to impact the kinematics of mandibular movements due to a need to adjust the combination of compression and shear stresses $\left[1^{\circ}\right]$. Furthermore, fracture propagation during mastication inside the food matrix strongly depends on its structure [2]. The number of fractures and consequently of food fragments seems mainly to depend on food toughness [3] with resistant food often favouring fracture propagation, resulting in greater comminution. In parallel, the many and well-documented individual chewing strategies 
Figure 1

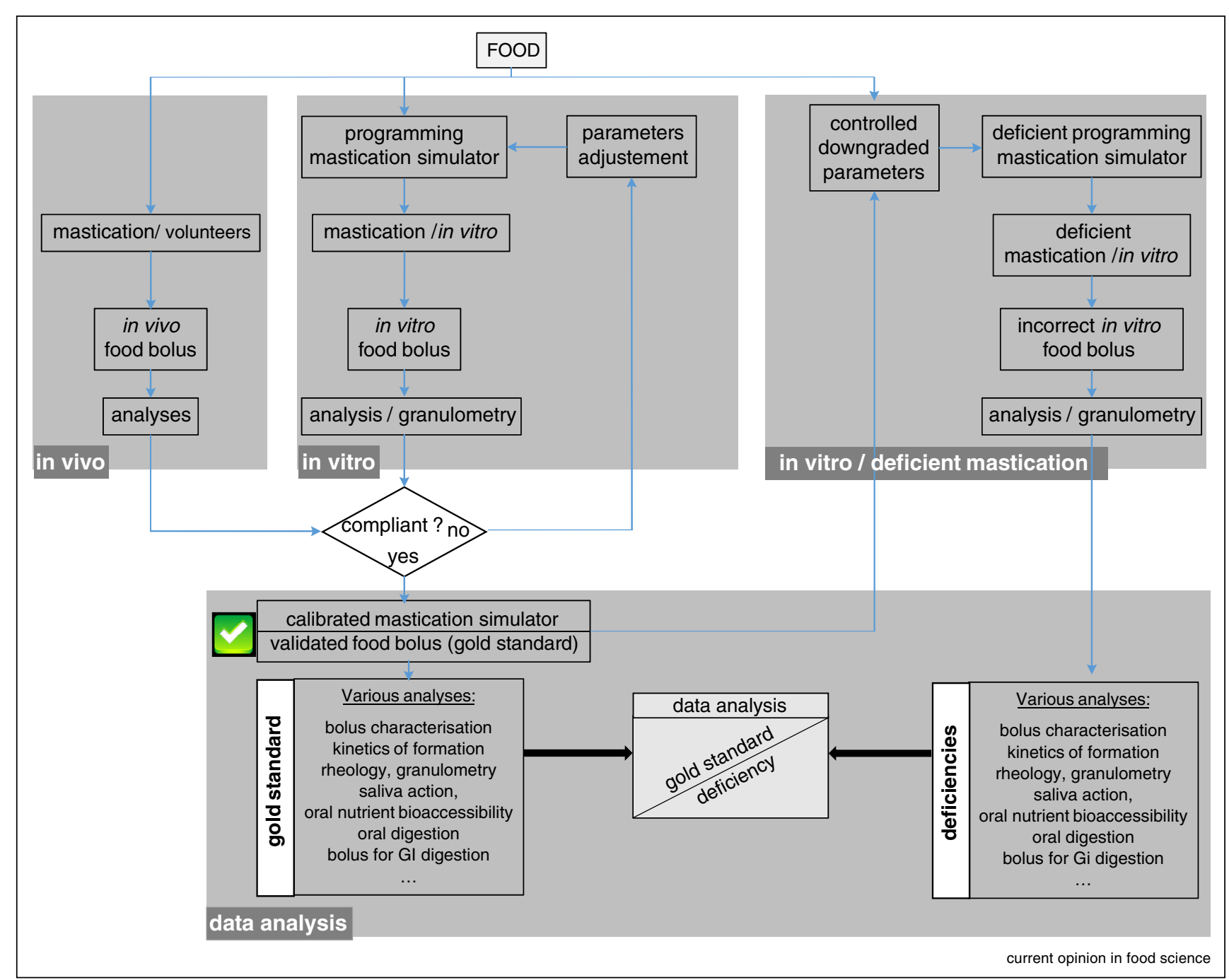

Flowchart displaying the key steps in development through sequential in vivo-in vitro actions, and validation stage of a mastication simulator before operating it to produce boluses for multiple purposes.

help to accomplish the mechanical food disruption. The end point of the masticatory sequence is determined by the intrinsic properties of the bolus. Thus, swallowing is initiated when the bolus has been perceived by the oral receptors to be ready for safe-swallowing. Thus the swallowing threshold is a combination of numerous physical dimensions including particle size, cohesiveness, elasticity, plasticity, moistening, intrinsic action of mucines and enzymes, among other factors. In particular, particles must be bound together by viscous forces rendering the bolus sufficiently cohesive $[4,5]$. This swallowing threshold is specific to each food.

In summary, the basic points to be considered, before simulation and according to the research strategy, are $\left[1^{\bullet}, 2,5\right]$ :
1) Mastication of solid food ends with a bolus swallowable without risk of mucosal injury and aspiration. For each food, a correct and specific granulometry, rheology and saliva impregnation characterize a swallowable bolus. In normal mastication, bolus particle size distribution is specific to food structure and similar between boluses from different subjects.

2) If such a bolus cannot be produced, mastication must be considered as impaired. At the individual level, two indicators sign for an impaired mastication: increased bolus granulometry above a certain threshold level and variation in frequency of the strokes while masticating a given food compared with normal mastication.

3) In subjects with perfectly healthy mastication, increasing either the force or the number of tooth strokes or the combination of compressing versus 
shearing constraints allow adapting to different food structures or to harder or more difficult food stuffs to chew.

4) Subjects with moderate impairment of the anatomical or physiological conditions of the masticatory apparatus can also succeed in making a viable bolus through a more demanding adaptation. Again, the adaptation relies on increasing the force, the number of tooth strokes or the constraint modes.

\section{Different kinds of simulation/reproduction of masticatory function}

\section{Biomechanical knowledge-oriented simulation}

Computer or computer-assisted models have often been elaborated to analyze the dynamics of biomechanical aspects of the masticatory function for dental, medical and therapeutic objectives and for understanding biological systems. It participates in predicting jaw movements, muscle activations, recruitment patterns and controls, resulting forces, or movements at the temporomandibular joint [6-12]. Recently, some digital investigations based on the discrete element method were conducted on the food breakdown pathways during oral processing and the establishment of links between food fragmentation and initial food structure [13].

Several mastication robots or mechatronic devices have been conceived and designed to study biomechanics of the masticatory process. Development of a series of mastication robots was carried out for quantitative and dynamic assessment of mechanical stress applied to oral elements during oral activity. The 'Waseda Jaw (WJ)' systems were mostly developed to analyze the mechanical effects of mastication on jaw bones in terms of position, force, velocities and muscle controls $[14,15]$. A second example of a mechatronic chewing device is of particular relevance since it can reproduce the entire suite of complex functions and movements involved during mastication, encompassing most of oral applications [16,17]. The main objective of this device was to propose a 'chewing robot' (Figure 2a) able to reproduce a molar trajectory in actual dimensions $\left[18,19,20^{\circ}\right]$. Aside from the area of food science, dentistry and specialists in dental materials developed tools to evaluate fatigue, resistance, wear or behaviour of restorative pieces under mechanical testing as close as possible to in vivo oral conditions [21-23].

Figure 2

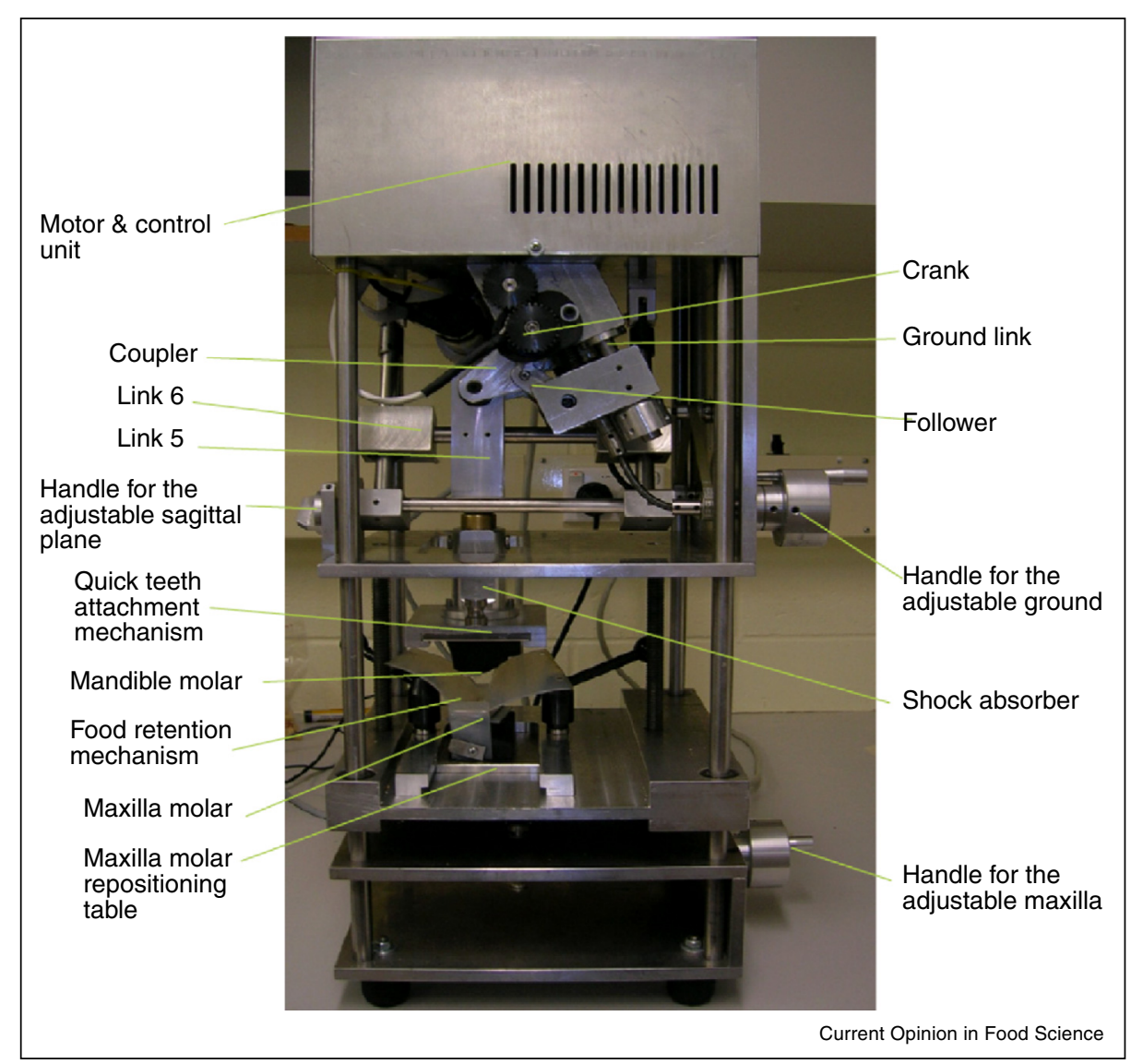

The 'chewing robot'.

Reproduced with authorization from [30]. 


\section{Food-oriented or bolus-oriented simulation}

The first attempts to mimic jaw movement with a main interest towards the food sample were equipment roughly designed to activate the upper jaw against the food sample for measuring mechanical properties of food texture or equipped for example with a piston presenting a cuspal angulation reflecting angles observed in the mouth $[24,25]$. This kind of machine, considered as providing objective methods for food evaluation, generally displayed significant correlation between sensory perception and mechanical measurement. Similarly, food science researchers tried to improve the first basic devices developed to describe food texture [26]. For example, the experimental 'crush chamber' was designed to include evaluation of acoustic, tactile and olfactory stimuli during crispbread mastication [27]; the 'BITE Master II' was elaborated to study the perception of cheese hardness during the very first chew [28], and an 'in vitro mouth model' was developed for the determination of salt release from the food matrix [29]. The 'chewing robot' (Figure 2a) was first developed to reproduce the mechanics of the chewing process but could also be proposed in the future to give a quantitative analysis of mechanical disruption allowing texture analysis of a food sample in nutritional questionings [30]. In addition, some simple instrumentation was developed for semi-solid food issues [31].

Since it leads to perception of flavour, the release of volatile aromatic compounds during food disruption is one of the issues most studied using chewing simulation [32-37]. In these different approaches, the liberation or retention of volatile molecules was measured in relation to the presence of saliva of known flow and composition. These needs induced specific requirements that were very challenging for the conception of a masticatory device. It led to debatable choices; for example, in terms of food disruption modalities, the volume of the artificial mouth, or the duration of masticatory sequence, to name a few. The 'artificial mouth' developed by Salles and collaborators (Figure 2b) is probably the most successful apparatus for measuring aroma release during chewing since it encompasses more physiological purposes than others [36,38]. The apparatus produces food breakdown due to two opposite tooth arches actuated in both vertical and horizontal/angular motions. Volatile retention is completed with a gas introduced into the system, allowing air sampling in synchronization with mastication events, as sniffing does in vivo. Food breakdown has only been 'validated' against peanut particle size observed in vivo in a very few number of subjects [36].

The 'AM ${ }^{2}$ apparatus' (Figure $3 \mathrm{~b}$ ) is the unique mastication machine focusing on the food bolus as the result of mastication while introducing most of the actual biomechanical masticatory features $[39,40]$. The $\mathrm{AM}^{2}$ apparatus thus permits simulation of mastication in various oral contexts and provides a complete food bolus recovery after mastication for further analysis. It produces a food bolus with properties similar to those of a bolus produced by in vivo mastication in numerous subjects ([41] - Figure 1). This kind of device can also be successively employed to investigate food science, physiological or nutrition fields such as nutrient bioaccessibility assessment or digestive process follow-up in link with oral food transformation ([42] - Figure 1).

\section{Figure 3}

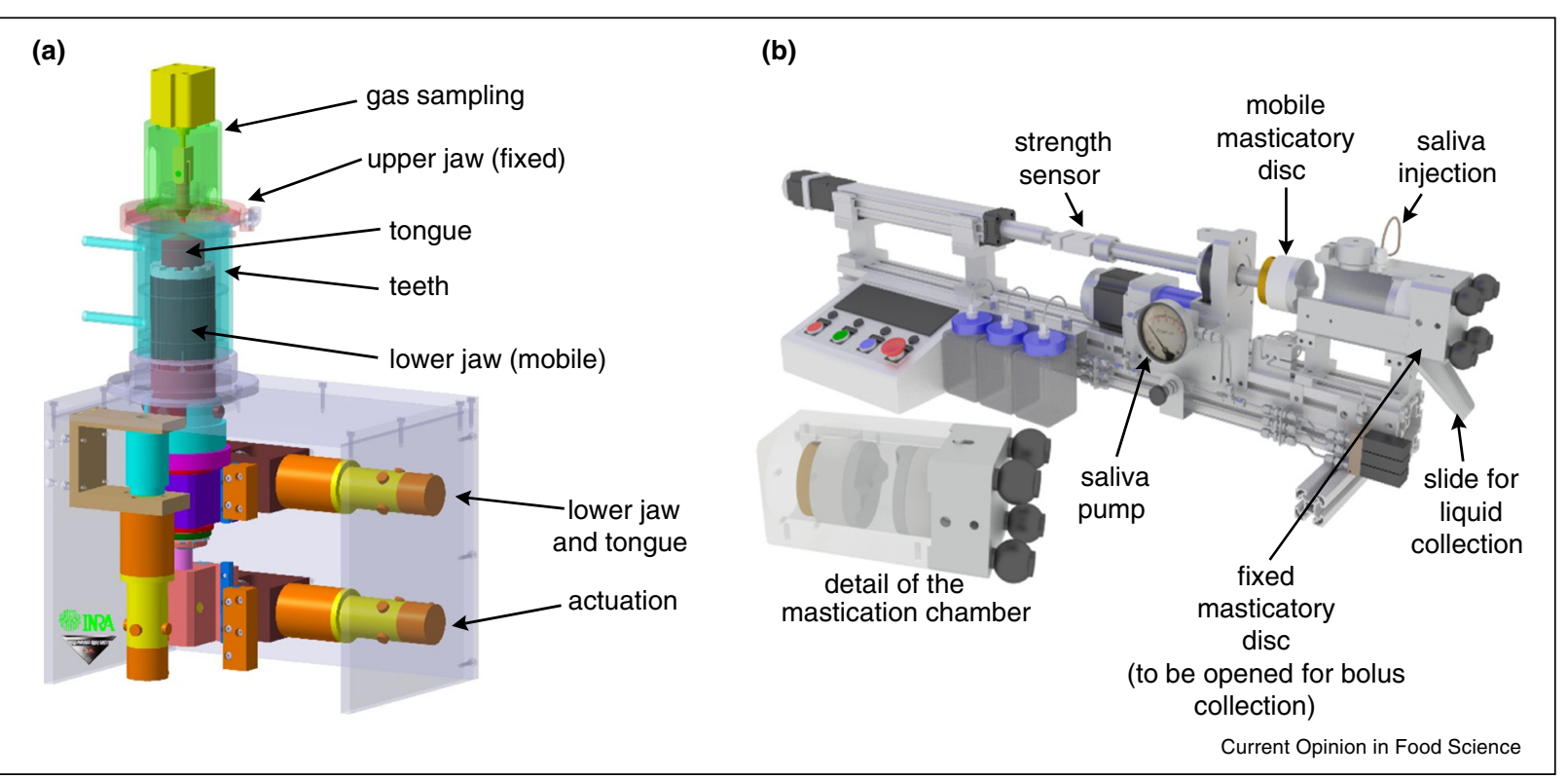

(a) The 'artificial mouth' (reproduced with authorization from [36]), and (b) the 'AM² masticator apparatus' [39]. 


\section{Biomechanical aspects of masticatory simulators}

Depending on the reason for using them, the various existing mastication simulators have differently set five key variables: teeth or equivalent, inside-mouth volume, saliva or equivalent, temperature control, and kinetic and stress modalities of functioning. The most crude simulation of tooth function is probably Mills's 'in vitro mouth model' that only compresses a food sample under a flat piston to measure the salt released in the liquid medium [29]. Other developers equipped their apparatus with teeth using either a complete human skull ('Waseda Jaw', [14]), patient's complete arcades ('Bite MASTER II', [28]), or series of molar teeth fixed on two opposite ring-shaped cylinder) 'artificial mouth', [36]). The major limit of this type of choice is that it under-estimates the role of the central nervous system in taking advantage of the complex anatomy of the tooth arches. The control of masticatory movements and forces performed by the nervous system cannot be replaced and this renders difficult the interpretation of what happens to the food sample in term of mechanical stress and strain. The experimental mouth proposed by Salles et al., with teeth organized on a circle-shaped design (Figure 3a), miscopies the normal human tooth contacts and offers more contacts between teeth and food than in a human mouth, making the estimation of the forces and constraints applied to the food samples difficult. It also renders difficult the recovery of the food particles that constitute the bolus. Consequently, it could probably cannot be used for other purposes than study of the dynamic release of volatiles during mastication. Finally, the use of dental arcades similar to the 'real' anatomy has not been shown to give better correlation between sensory and instrumental hardness assessment than when food hardness is measured by a classical compression test. It may also introduce another source of variation by its inability to maintain the food particles between the teeth. This limit was accounted for in the artificial mouth of Salles's team by a tongue placed at the centre of the ring supporting the teeth, programmed to place food particles on the teeth. This design, however, does not gather food particles in a bolus since particles are inevitably distributed over the full ring [36]. Despite these limits, this latter device seems to be the most advanced for the study of aroma release during oral food breakdown. The systems equipped with cutting blades [37] or triangular-shaped elevations [27], cannot be considered to mimic masticatory action due to the absence of a lot of components of movement, of 'tooth' elements and no control of the stress applied to the food sample. In the $\mathrm{AM}^{2}$ apparatus, tooth function is reproduced but not tooth anatomy. Tooth action is made by two opposite triangular forms whose active surfaces are similar to the sum of the molar and

Figure 4

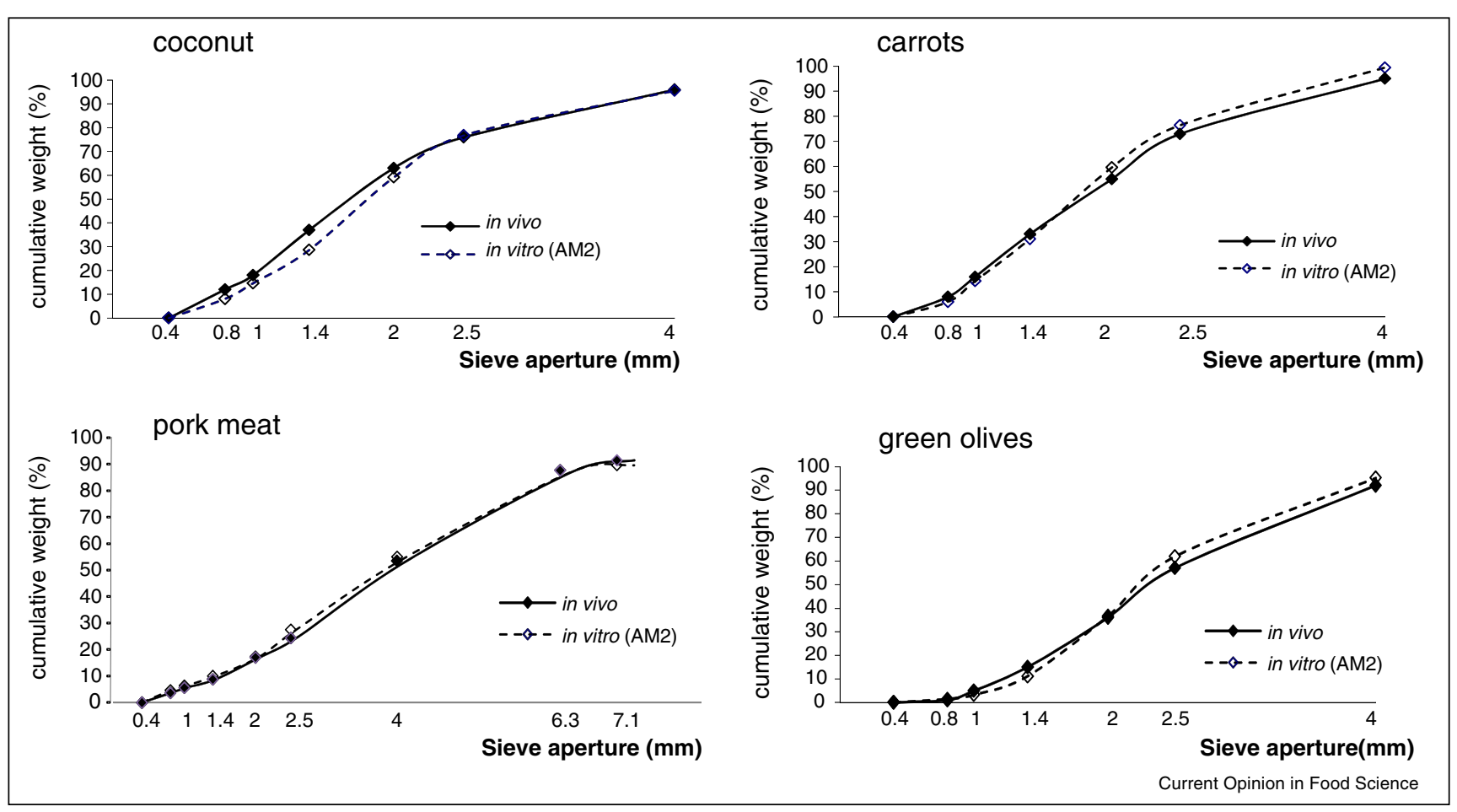

Comparison of particle size distributions obtained in food boluses collected at the end of mastication in vivo in volunteers with normal dentitions or in vitro with the $\mathrm{AM}^{2}$ masticatory apparatus. 
premolar surface areas involved when chewing a standard bolus. These 'tooth' elements are actuated by translation and rotational movements to ensure correct impact on food and gathering of the particles before tooth confrontation [39].

Three other key points are important in the development of a simulator. Saliva should be used. Ideally, its composition, flow distribution along masticatory sequence and total injected volume should mimic those seen in the human mouth. The volume of the 'masticatory chamber' should be similar to the volume of the mouth and a possibility of controlling the oral temperature should exist. Saliva, volume and temperature items are fundamental for studying aroma or nutrient release and food texture measurements. Not all apparatuses are equipped for these controls and this may affect data interpretation.

The final items that should be considered are kinetic factors and constraint modalities of functioning. Various degrees of freedom have been chosen depending on the main purpose for using the apparatus (aroma release, food texture/bolus measurements, dental training, for example). Obviously, complex mandibular movements adjusted to the food being chewed cannot be completely reproduced. Complete feedback control is always absent although it has been sought while studying the first stroke [28]. This requirement has been addressed differently by choosing to reproduce or control the mechanical function, jaw movements, imitation tooth anatomy and applied forces $[30,36,39]$, or by applying fracture propagation knowledge to food matrix during disruption (tooth action in mechanical terms) in order to select appropriate stressstrain conditions [39].

\section{Validation of mastication devices by food bolus analysis}

The food bolus is the main focus of interest in most topics in food science research. Food bolus analysis is at the crossroads between food structure, food formulation, food perception, food oral processing and the further stages of digestion. The ready-to-swallow bolus contains information about the oral conditions of its formation. In addition, it constitutes the vector for nutrients. For all these reasons, a mastication simulator provides a valuable contribution since it allows recovering the totality of the food bolus at the end of the masticatory sequence. During mastication, food sample is drastically disrupted to form a cohesive entity, which can be swallowed easily and without risk of particle aspiration. As particles are formed, they are mixed with saliva. During this process, the smaller the food particles, the greater the surface contacts between food and saliva, favouring the access of salivary enzymes to substrates. The ready-to-swallow final bolus is composed of particles of various sizes and saliva or juice released from the food matrix. The bolus can be analyzed for particle size distribution, a major characteristic of food disruption.

Any chewing device used to provide food boluses has to be validated against human mastication (Figure 4). Such validation has not been conducted for many of the proposed systems. This deficiency is striking in digestion studies, which are generally operated without a specific masticatory apparatus or with food particles coarsely ground or minced and mixed with saliva or enzyme during an uncontrolled or unjustified time, to obtain what must be considered as a fortuitous food bolus [43]. Mishellany-Dutour et al. [41] validated the $\mathrm{AM}^{2}$ apparatus by comparing particle size distribution and median particle size of an in vitro bolus with a bolus made in vivo by selected subjects with normal dentitions, a correct occlusion and a normal saliva flow (Figures 4 and 5). Some bolus rheological properties, hardness or cohesiveness, for example, are also very informative of the suitability of the bolus to be safely swallowed [5] and should also be used for in vivol in vitro validation purposes.

\section{Figure 5}

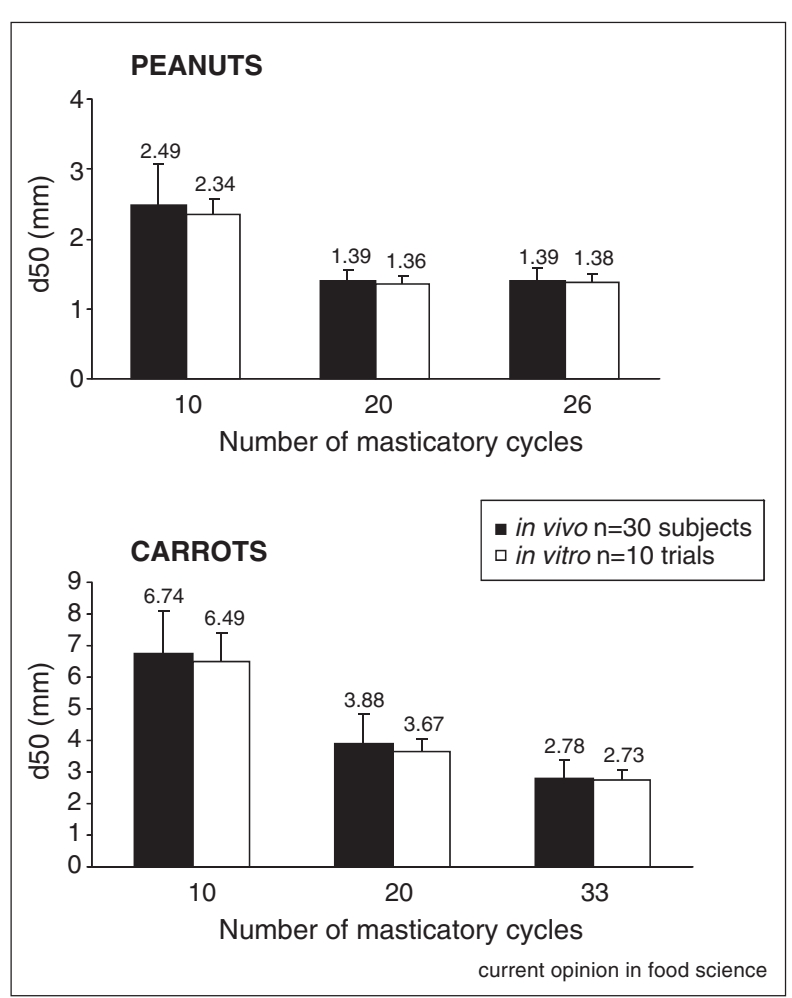

Median particle size (d50 values) of food boluses collected after 10 cycles, 20 cycles of at the end of the masticatory sequence, in vivo in volunteers with normal dentitions and in vitro with the $\mathrm{AM}^{2}$ masticator apparatus.

Reproduced with authorization from [40]. 


\section{Conclusion}

In summary, when the major objective of simulation is to reproduce the biomechanics of jaw movements and forces, mathematical models or robots are more appropriate. When the objective is to study the resulting food bolus, a device reproducing masticatory parameters and correct food disruption is a better option. The specifications and technical limits for a simulation device depend on the primary research purpose: aroma release, food texture assessment, production of a food bolus providing for subsequent digestion analyses, the impact of a change in food formulation on bolus, biomechanical analysis of stress applied to oral elements and other factors are specific questions. Nevertheless, taking account of the main laws governing the biomechanical mechanisms of the masticatory processes and the dynamics of bolus properties are always needed [26]. Knowing the features associated with a correct use of an in vivo bolus simulator allows the preparation of a realistic bolus for subsequent analyses (Figure 1). In addition, it favours interpretation of the results. Obviously, all apparatuses must be validated before use and this essential step can only be done by comparing boluses obtained in vivo in a sufficient number of individuals versus boluses obtained in vitro. Clearly, a mastication simulator cannot reproduce the large range of mastication strategies observable in human. The apparatus is therefore assumed to reflect average mastication. A well-designed apparatus can be employed to investigate the kinetics of bolus formation in terms of particle size, rheological behaviour, saliva impregnation, compound release or biochemical modification, as a function of food structure, food formulation and processing, or even to simulate several dental or ageing conditions (Figure 1). Mimicking oral steps using a kitchen food processor or a static oral digestion apparatus, as is too often done in digestion studies, cannot produce a realistic bolus for a majority of solid foods, especially if considering specific populations such as the elderly or infants, because it cannot produce a particle size distribution and cannot reproduce the dynamics of bolus formation. If these complex oral steps are overlooked, data obtained from bolus analyses in digestion studies or for texture assessment during the whole masticatory sequence could be biased.

\section{Acknowledgements}

The authors want to thank O. François (University of Auvergne) for his involvement in the development of the $\mathrm{AM}^{2}$ apparatus and in preparing the figures; and P. Riordan for English revision.

\section{References and recommended reading}

Papers of particular interest, published within the period of review, have been highlighted as:

- of special interest

$\bullet$ of outstanding interest

1. Woda A, Foster K, Mishellany A, Peyron MA: Adaptation of

- healthy mastication to factors pertaining to the individual or to the food. Physiol Behav 2006, 89:28-35.
This synthesis presents what results and physiological laws governing mastication must be known before simulation of masticatory process.

2. Jalabert-Malbos ML, Mishellany-Dutour A, Woda A, Peyron MA: Particle size distribution in the food bolus after mastication of natural foods. Food Qual Prefer 2007, 18:803-812.

3. Agrawal KR, Lucas PW, Prinz JF, Bruce IC: Mechanical properties of foods responsible for resisting food breakdown in the human mouth. Arch Oral Biol 1997, 42:1-9.

4. Prinz JF, Lucas PW: An optimization model for mastication and swallowing in mammals. Proc Royal Soc Lond Ser B Biochem 1997, 44:1715-1721.

5. Peyron MA, Gierczynski I, Hartmann C, Loret C, Dardevet D, Martin N, Woda A: A likely role of physical bolus properties as sensory inputs in swallowing triggering. PLOS ONE 2011 6:e21167.

6. Osborn JW, Baragar FA: Predicted pattern of human muscle activity during clenching derived from a computer assisted model: symmetric vertical bite forces. J Biomech 1985 , 18:599-612.

7. Baragar FA, Osborn JW: Efficiency as a predictor of human jaw design in the sagittal plane. J Biomech 1987, 20:447-457.

8. Koolstra JH, van Eijden TM, Weijs WA, Naeije M: A threedimensional mathematical model of the human masticatory system predicting maximum possible bite forces. J Biomech 1988, 21:563-576.

9. Gallo LM, Airoldi GB, Airoldi RL, Palla S: Description of mandibular finite helical axis pathways in asymptomatic subjects. J Dent Res 1997, 76:704-713.

10. Slagter GEC, Otten E, van Eijden TMGJ, van Willingen JD: Mathematical model of the human jaw system simulating static biting and movements after unloading. J Neurophysiol 1997, 78:3222-3233.

11. Koolstra JH, van Eijden TMGJ: A method to predict muscle control in the kinematically and mechanically indeterminate human masticatory system. J Biomech 2001, 34:1179-1188.

12. Gal JA, Gallo LM, Palla S, Murray G, Klineberg I: Analysis of human mandibular mechanics based on screw theory and in vivo data. J Biomech 2004, 37:1405-1412.

13. Hedjazi L, Martin CL, Guessasma S, Della Valle G, Dendievel R: Experimental investigation and discrete simulation of fragmentation in expanded breakfast cereals. Food Res Intern 2014, 55:28-36.

14. Kato I, Takanisi A, Asari K, Tani T: Development of artificial mastication system. Construction of one degree of freedom antagonistic muscle model WJ-O. Anat Anz 1988, 165:197-203.

15. Usui T, Maki K, Toki Y, Shibasaki Y, Takanobu H, Takanishi A, Hatcher D, Miller A: Measurement of mechanical strain on mandibular surface with mastication robot: influence of muscle loading direction and magnitude. Orthod Craniofac Res 2003, 6(Suppl. 1):163-167.

16. Xu WL, Bronlund JE, Kieser JA: Choosing new ways to chew. IEEE Robot Autom Mag 2005, June:90-98.

17. Pap JS, Xu WL, Bronlund J: A robotic human masticatory system: kinematics simulations. Int J Intell Syst Technol Appl 2005, 1:3-17.

18. Daumas $\mathrm{B}, \mathrm{Xu} \mathrm{WL}$, Bronlund J: Jaw mechanism modelling and simulation. Mech Mach Theory 2005, 40:821-833.

19. Xu WL, Bronlund JE, Potgieter J, Foster KD, Röhrle O, Pullan AJ, Kieser JA: Review of the human masticatory system and masticatory robotics. Mech Mach Theory 2008, 43:1353-1375.

20. Xu W, Bronlund JE: Mastication Robots. Biological Inspiration to

- Implementation. Studies in Computational Intelligence. Berlin: Springer; 2010.

This book depicts how the use of a robotic simulation of mastication allows the study of biomechanics of the masticatory system.

21. Conserva E, Menini M, Tealdo T, Bevilacqua M, Pera F, Ravera G, Pera P: Robotic chewing simulator for dental materials testing 
on a sensor-equipped implant setup. Int J Prosthodont 2008, 21:501-508.

22. Raabe D, Alemzadeh K, Harrison AL, Ireland AJ: The chewing robot: a new biologically-inspired way to evaluate dental restorative materials. Conf Proc IEEE Eng Med Biol Soc. 2009:6050-6053.

23. Steiner M, Mitsias ME, Ludwig K, Kern M: In vitro evaluation of a mechanical testing chewing simulator. Dent Mater 2009, 25:494-499.

24. Friedman HH, Whitney JE, Szczesniak AS: The texturometer - a new instrument for objective texture measurement. J Food Sci 1963, 28:390-403.

25. Wang JS, Stohler CS: Textural properties of food used in studies of mastication. J Dent Res 1990, 69:1546-1550.

26. Morell $P$, Hernando I, Fiszman SM: Understanding the relevance of in-mouth food processing. A review of in vitro techniques. Trends Food Sci Technol 2014, 35:18-31.

27. Winquist F, Wide P, Eklöv HC, Lundström I: Crisbread quality evaluation based on fusion of information from the sensor analogies to the human olfactory, auditory and tactile senses. $J$ Food Process Eng 1999, 22:337-358.

28. Meullenet JF, Gandhapuneni RK: Development of the BITE Master II and its application to the study of cheese hardness. Physiol Behav 2006, 89:39-43.

29. Mills T, Spyropoulos F, Norton IT, Bakalis S: Development of an in-vitro mouth model to quantify salt release from gels. Food Hydrocoll 2011, 25:107-113.

30. Xu WL, Lewis D, Bronlund JE, Morgenstern MP: Mechanism, design and motion control of a linkage chewing device for food evaluation. Mech Mach Theory 2008, 43:376-389.

31. Prinz JF, Janssen AM, de Wijk RA: In vitro simulation of the oral processing of semi-liquid foods. Food Hydrocoll 2007, 21:397-401.

32. Nassl K, Kropf F, Klostermeyer H: A method to mimic and to study the release of flavour compounds from chewed food. Z Lebensm Unters Forsch 1995, 201:62-68.

33. van Ruth SM, Roozen JP, Nahon DF, Cozijnsen JL, Posthumus MA: Flavour release from rehydrated french beans
(Phaseolus vulgaris) influenced by composition and volume of artificial saliva. Z Lebensm Unters Forsch 1996, 203:1-6.

34. Deibler KD, Lavin EH, Linforth RS, Taylor AJ, Acree TE: Verification of a mouth simulator by in vivo measurements. $J$ Agric Food Chem 2001, 49:1388-1393.

35. van Ruth SM, Buhr K: Influence of mastication rate on dynamic flavor release analysed by combined model mouth/proton transfer reaction-mass spectrometry. Int J Mass Spectrom 2004, 239:187-192.

36. Salles C, Tarrega A, Mielle P, Maratray J, Gorria P, Liaboeuf J, Liodenot JJ: Development of a chewing simulator for food breakdown and the analysis of in vitro flavor compound release in a mouth environment. J Food Eng 2007, 82:189-198.

37. Arvisenet G, Billy L, Poinot P, Vigneau E, Bertrand D, Prost C: Effect of apple particle state on the release of volatile compounds in a new artificial mouth device. J Agric Food Chem 2008, 56:3245-3253.

38. Mielle P, Tarrega A, Sémon E, Maratray j, Gorria P, Liodenot J J, Liaboeuf J, Andrejewski JL, Salles C: From human to artificial mouth, from basic to results. Sens Actuators B 2010, 146:440-445.

39. Woda A, Mishellany-Dutour A, Batier L, Francois O, Meunier JP, Reynaud B, Alric M, Peyron MA: Development and validation of a mastication simulator. J Biomech 2010, 43:1667-1673.

40. $\mathrm{AM}^{2}$, Artificial Mastication advanced Machine website; URL: http://masticateur.u-clermont1.fr/.

41. Mishellany-Dutour A, Peyron MA, Croze J, François O, Hartman C, Alric M, Woda A: Comparison of food boluses prepared in vivo and in vitro by the mastication simulator: AM2. Food Qual Prefer 2011, 22:326-331.

42. Hennequin A, Peyron MA, Ferreira C, Aubry L, Santé-Lhoutellier V: Addition of fibers in Frankfurters modifies the ready-toswallow food bolus properties and oral bioaccessibility of nutrients after in vitro mastication. In Proceedings of 61st International Congress of Meat Science \& Technology (ICOMST); Clermont-Ferrand, France, August: 2015.

43. Minekus M, Alminger M, Alvito P, Ballance S, Bohn T, Bourlieu C Carrière F, Boutrou R, Corredig M, Dupont D et al.: A standardised static in vitro digestion method suitable for food - an international consensus. Food Funct 2014, 5:1113-1124. 